\title{
Motivational Factors Leading Young Saudi Females to Become Bilinguals
}

\author{
Ana Gil Garcia ${ }^{1} \&$ Mercedes Cardella ${ }^{2}$ \\ ${ }^{1}$ Northeastern Illinois University, Chicago, IL, USA \\ ${ }^{2}$ Prince Mohammad Bin Fahd University, Al-Khobar, KSA \\ Correspondence: Ana Gil Garcia, Northeastern Illinois University, Chicago, IL, USA.
}

Received: February 7, 2017

Accepted: May 10, 2017

Online Published: May 26, 2017

doi:10.5430/irhe.v2n2p1

URL: https://doi.org/10.5430/irhe.v2n2p1

\begin{abstract}
The push for English acquisition has made countries rethink their internal academic curriculum affairs across all levels of education, K-21. Traditionally, most countries used their native official language as the mode of instruction in the classroom. In recent years, due to technological innovation, globalization and social networking, higher education institutions have created ways to adapt to and accommodate an increasing demand for English as a worldwide business language. English, which has in the past century become the second language of the world, has unofficially become the number one language of the global village, both in real terms and through the media. The Kingdom of Saudi Arabia is not an exception. Many universities in the Kingdom have responded to the internationalization of the curriculum by facilitating mechanisms to deliver full degrees in English and have westernized their modes of instruction. But, what mechanisms have influenced the population to make English the preferred language for teaching and learning? For the purpose of this qualitative research, 67 freshman female Saudi students were asked to write about their motivation to become bilingual in English. To collect data, students wrote essays about their motivation and inspirations that drove them to learn English as a second language. The methodology incorporated the use of the five W questions approach: What, Who, When, Where and Why. Surprisingly, the primary forms of motivation to learn the language were parents at home. The second factor was social media outlets offering individuals the ability to communicate with the outside world, and thirdly, personal and professional reasons to make them more competitive and marketable in todays' demanding business world.
\end{abstract}

Keywords: English, bilingual, motivation, Saudi females, family

\section{Introduction}

Schools in Saudi Arabia and elsewhere have sustained the teaching of English as a second language or foreign language (ESL/EFL) to students at increasingly earlier ages. As English has increasingly become the means towards success in the globalized world, educational systems worldwide are spending significant time, resources, and human effort on the teaching and learning of English as a either foreign language or second language. The push for learning English has spread among even young learners of the language. This trend is global, as geographical and state borders have become less distinct on the platforms made available through technologically driven media. More than just a personal interest, from pre-k to university classrooms, from formal to informal education, the English language has a profound meaning attached: the meaning of the power.

Public and private systems of education worldwide have made tacit agreements to teach the language of the world, English. Millions of research studies have reinforced that English is the primary means for communication across borders and cultures. Many types of educational programs are formally and informally planned with the sole purpose of teaching English as either a foreign language or a second language. The modes of operation for teaching the language vary. From study-abroad programs to private tutoring, from technology-based individualized learning to technology-based cooperative groups, multiple and varied delivery modes are used. In Saudi Arabia, as in any other country in the world, the technicalities of teaching English to the K-21 population have also reached the unimaginable. The government has promoted the learning of foreign languages, with English as the number one choice. Schools in KSA are rapidly adapting to government and social demands. 
The desire to learn English as a second language in the Arab world has become increasingly popular over the last several decades. It is contended in Norbert Schmitt's An Introduction to Applied Linguistics, that the motivations for learning a language cannot be reduced to any variables such as gender, subject major or geographical location. Rather, motivations are argued to be the "key learner variable because without it, nothing happens" (Schmitt, $2002 \mathrm{p}$. 172). In the case of Saudi Arabia, the motivations for learning English have become a serious research concern in the recent years. In the past, there was very little EFL research conducted about Saudi Arabia. However with the rise of English language institutes and the implementation of English preparatory year programs in universities, an increased awareness can be observed regarding the subject matter. Researchers are intrigued to understand and evaluate the motivational factors of learning English amongst Saudi University undergraduates. It is observed that amongst female undergraduates in Saudi Arabia, extrinsic motivations for language acquisition exceed intrinsic motivations.

\subsection{The Kingdom of Saudi Arabia}

The Kingdom of Saudi Arabia is the largest Arab state in southwest Asia. The country is the world's second largest oil producer and exporter. According to the World Factbook (CIA, 2015), Saudi Arabia was the birthplace of the religion of Islam. The Arabic speaking country of 27 million inhabitants is a monarchy, in which since the establishment of the Kingdom, leaders are appointed from the family of Al Saud. More than $30 \%$ of the Saudi population are expatriates (immigrants). The legal system of the country has been based on an interpretation of Sharia law (Islamic law) since 1992. There are 13 provinces, and Al Khobar is one of the twelve major cities located in the Eastern province, in which the study took place.

Saudi Arabia is one of the most traditional and insular Arab nations that has successfully avoided change (Foley, 2015). King Abdulaziz, in order to keep his family in power, set up some contingencies in his country to ensure successful retention of that power. Among uniting the tribes and gaining their allegiance, he also greatly subsidized many things for the Saudi people essentially causing a reliance on welfare. The Kings, and especially the most recent King Abdullah mastered a justification of the use of western technology and retention of Islamic traditions at the same time. He thereby allowed transformation without change.

\subsubsection{Prince Muhammad bin Fahd University}

Al-Khobar is the residence of Saudi Aramco, the world's largest oil company, and many higher education universities, including Prince Muhammad Bin Fahd University (PMU), the research site, a private higher education institution officially established in October 08, 2008. It has a male and female campus. The institution has four colleges and its motto is "Making history...Building leaders". PMU offers thirteen undergraduate and three graduate degree programs. The study materialized in the female campus, at the Department of Core and Humanities that is responsible for the general education courses of the entire university curriculum.

\section{Literature Framework}

\subsection{The Language of Globalization in Saudi Arabia}

In order to understand the motivational factors of learning English amongst Saudi female students, we must look at EFL theories that focus on the term motivation itself. The Socio-educational Model, a scholarly article written and re-visited by Robert C. Gardner in 2006, outlines two fundamental categories to understand motivation in the EFL environment. The first is termed 'intrinsic motivations', which explores the internal reasons behind learning a foreign language (Gardner, 2006). Factors such as having a sincere interest in the language, customs and traditions of a given culture or the desire to partake in an activity that develops knowledge exemplifies the intrinsic motives in language acquisition. Extrinsic motivation identifies the external motivational factors to learning a new language (Gardner, 2006). Gardner's socio-educational model was created to specifically look at language learning in both foreign and second language learning contexts. The theory contains three components. The first sheds light on the integrative factors of learning a language. The second reveals the attitudes towards learning situations and explores the educational setting, and the final step of his theory assesses the motivation behind language learners (Gardner, 2010). Gardner's findings suggest that the extrinsic motivations to language acquisition are reflective of the environment, and are often for utilitarian reasons. Moreover, his findings disclose that foreign language learners are more interested and focused on the extrinsic motivations to learn a language. For instance, Gardner highlights that individuals have more of an interest to learn a language in order to advance in their careers, pass an internationally recognized examination, and travel purposes or for the financial incentives that are accompanied with English. While both types of motivational factors are important to EFL learners, simple and complex models determine that extrinsic motives to language acquisition are stronger. 
Gardner's findings can be exemplified in The Kingdom of Saudi Arabia. With the increase in language institutes and University Preparatory Year Programs, the demand to learn English for extrinsic motivational purposes is increasing. Personal anecdotes from a University located in the Eastern Province reveal that many undergraduate students want to learn English, as it can allow them to become exceptional competitors in the global job market, or enable them to study abroad at well-renowned Universities. Moreover, with English for specific purposes (ESP) programs such as SABIC and Aramco's scholarship program, students are enrolled in an intensive English program to prepare them for undergraduate studies in the United States of America. Ultimately, these programs will prepare these individuals to work for the world's largest petroleum and Natural Gas Company and Saudi Arabia's largest employer-Aramco. Although much research and debate has surfaced within the recent years indicating that intrinsic motivational factors are far more important than extrinsic orientations (Moskovsky \& Alrabai, 2009)- women learning English in KSA are an interesting case study of the differences and implications of intrinsic and extrinsic motivational factors in acquiring English. Gardner (2006) is careful in his analysis, and posits that although the role of intrinsic motivation is important in the EFL learning process, extrinsic motivations takes precedence. With the conclusion that the globalization of the English language seems to be an inevitable process, it makes sense to focus on the functional reasons of learning the language.

\subsubsection{The Globalization of English in Social Media and Communication Outlets}

A review of the literature indicates that there is very little academic discourse on the affects of social media and communication outlets in Saudi Arabia. However, Anne Johnson (2009) highlights the universality of the English language in today's communication outlets on a global level. In "The Rise of English: The Language of Globalization in China and the European Union", Johnson stipulates that "with the increase of global interaction, there has been a demand for efficient communicative technology that extends itself across lingual borders" (Johnson, 2009, p.140). Moreover, the author articulates that with the expansion of transnational organizations and the language's association with all things "modern", vis-à-vis the World Wide Web and American pop culture, communication outlets are exclusively in English and the world is forced to adapt to it. As The Economist described it: "English is a basic skill of modern life comparable with the ability to drive a car or use a personal computer" (The Economist, 2001).

This widespread belief is apparent amongst the youth of Saudi Arabia. An extrinsic motivation factor that Gardner does not postulate but is articulated in Johnson's piece is the desire to communicate in a cross-cultural context. Young Saudi females are joining English-oriented communication networks such as Facebook, Instagram, Twitter and Snapchat as a means to connect with people globally, to follow global trends in fashion and culture and, simply, to stay relevant. While the author offers an impressive overview of the globalization of English in communication outlets, it does present some shortcomings. Johnson relies on a cosmopolitanism framework to convey her arguments. Cosmopolitanism theory suggests a belonging to a universal community amongst all human beings, regardless of their geographical location. This framework can be problematic as it suggests that all beings have equal access and equal opportunity to learn English, and as a result are able to enjoy the global communicative benefits. Moreover, with this global framework, the author focuses on China and Europe and fails to explore other pertinent regions in the dialectic. Seeing that a "universalist" approach was the methodology of choice, regions such as The Middle East and North Africa who have heavily relied on the use of social media outlets should have been explored. Nonetheless, through the use of case studies, interviews and literature-based research, Johnson articulates a very important theme, the role of English-dominated communication outlets and its widespread relation to modernity.

\subsubsection{The Role of the Family}

In a society that is indicative of honor, it should come as no surprise that the role of the family is one of the reasons why Saudi female EFL learners want to learn English. In "Intrinsic Motivation in Saudi Learners of English as a Foreign Language", Christo Moskovsky and Fakieh Alrabai (2009) argue that in the EFL classroom, one of the Saudi student's intrinsic motivations to learn English is the ability to impress their family and friends with their English skills. This competitive nature amongst Saudi students serves as an intrinsic motivational factor to master the English language. To be able to converse in a tongue that is foreign amongst their predecessor's, exemplifies as an elite social status amongst relatives and peers. Being able to have the opportunity to study English can open the doors to endless opportunities and financial security both in the Kingdom and abroad. Young female Saudi's measure their success through their parent's recognition and Saudi parents take pride in their children's achievements Renard, 2013). However, due to the internal nature of Saudi tribal culture, where features such as inter-tribal marriage and family name and honor are still hallmarks of the culture, learning English is not allowed to be a cultural passport to allow a change in values or behaviors. Students return from their experiences abroad and are expected to 
re-adjust to Saudi life. English may be learnt as a language, but it cannot interfere with cultural values. While the authors accentuate the intrinsic factors of motivation, they overlook the external factors of understanding motivation and the role and expectations that Saudi families take part in. However, through the use of qualitative analysis and the authors' specificity in Saudi Arabia, they contribute relevant and valuable content to the subject matter.

In summary, through Gardner's socio-educational model and Johnson's depictions of the role that English plays in modern communication outlets, it is evident that extrinsic motivations takes precedence in language acquisition than intrinsic motives. Moskovksy and Alrabai (2009) offer interesting intrinsic motivations of language acquisition amongst young Saudi learners but ultimately reveal that extrinsic motives surpass its counterpart. In Saudi Arabia, this is especially true amongst female learners because they are aware that studying English can serve as an educational opportunity to gain a level of independence-which is a recent phenomenon in the region. In other words, if women learn English, they will acquire potential financial independence through employment. Whether the focus of extrinsic motivation is to their benefit remains unknown. However, the region is undergoing a transformation and it will be interesting to see whether extrinsic motivational factors will remain the dominant motivational factor to language acquisition or whether intrinsic pursuits will rise.

The learning of a second language is a complicated task affected by external and internal forces. Undoubtedly, motivation is one of the primary forces influencing second language learning. Most literature reinforces that motivation is broadly recognized as an important aspect which determines the success and level of second language learning. With high motivation, the proficiency in second language is also high. For the previous reasons, the researchers of this study explored, based on personal narratives, the motivational factors that ignited young Saudi female students to learn English and become bilinguals.

\section{Methodology}

In the Learning Outcomes and Assessment course, the researchers asked sixty-seven Saudi freshman female students to write their own stories about becoming bilingual. An internal narrative, according to Gall, Gall \& Borg (2010) is a self-talk, a personal talk that an individual engages in during particular moments whether he/she is aware or not. The Saudi female students were directed to write an assignment, an essay, about the type of motivation used as a driving force to learn English in order to be bilingual. The researcher, the same instructor of the course, aspired to better understand the female students' life experiences and also to analyze their ability to understand and generate language.

\subsection{The Narrative Writers}

A purposeful sampling procedure was used to examine the narratives created by sixty seven female students whose age ranged from 18 to 20 years old, who are native of Saudi Arabia, whose first language is Arabic and their second language is English that was either learned at the K-12 private schools, summer camps abroad, and or at home from parents who speak English on a daily basis. They are freshman students who attended the English Preparatory Program of PMU for at least one semester before being immersed directly in the higher education classroom.

\subsubsection{Research Design}

A Narrative Research design defined as "the systematic study and interpretation of stories of life experiences" (Gall, Gall \& Borg, 2010, p. 557). Within the narrative research design, the narrative identity approach was utilized which refers to a sense of self that evolved from the personal stories that the Saudi girls constructed from her own experiences with the second language acquisition.

\subsubsection{The Structure of Narratives}

The language model used in social contexts by Labov and Waletsky (1967) was used to structure and analyze the narratives written by the female students. The model begins with a brief introduction (abstract), followed by the 5 Ws (who, when, what, where, and why). In the process, the writer narrates a longer segment that tells the story (complication) followed by an explanation on the meaning of the story (evaluation).

\subsubsection{The Collection of the Narratives}

The Saudi female freshman students were asked to write their personal stories or narratives on their motivation to learn English in order to become bilingual. The 2-page personal narrative was one of the six assessments required by the Learning Outcomes and Assessment course of one-credit, and one-hour daily class. The students were instructed to write an abstract, to respond to the $5 \mathrm{Ws}$ questions, to think about the complication, and the final response to the What (evaluation) of their own learning process to become bilingual. 


\subsubsection{The Analysis of Narratives}

The data analysis varied depending on whether the narrator wanted to describe, or explain, or evaluate their stories. The stories constructed based on the 5-Ws approach; therefore, the analysis followed the same structure. The researchers did not take word-by-word story as recounted by the research participant. Instead, the researchers retold the participants' stories so that the group of stories became an organized series of events, settings, characters, thoughts, and emotions.

\section{Findings and Discussion}

After reading sixty-seven narratives and grouping them according to the $5 \mathrm{Ws}$ (who, what, when, where, and why), the researchers located the coding frames and the themes that characterized each of the coding frames. Table 1 summarizes the coding frames and themes found in the narratives. Below are seven common themes that motivate Saudi females to learn English as a second language and ultimately, become bilingual:

Table 1 . Common themes constructed in the narrative identity stories

\begin{tabular}{|c|c|c|}
\hline Coding Frame & Theme & $\begin{array}{l}\text { Rank } \\
\text { Order }\end{array}$ \\
\hline Labor market & $\begin{array}{l}\text { To increase chances in obtaining better job positions } \\
\text { with KSA and abroad }\end{array}$ & 1 \\
\hline Personal communication & $\begin{array}{l}\text { To be able to communicate with } \\
\text { foreigners/expatriates }\end{array}$ & 2 \\
\hline English-speaking sibling & $\begin{array}{l}\text { Older sibling or parent that has studied abroad and it } \\
\text { has encouraged them to follow suit and learn the } \\
\text { English language }\end{array}$ & 3 \\
\hline Family encouragement & $\begin{array}{l}\text { Family member encouraging them to learn English, } \\
\text { as it can broaden their horizons and allow for better } \\
\text { opportunities than what they had }\end{array}$ & 4 \\
\hline Travel purposes & $\begin{array}{l}\text { English is an international language and can be used } \\
\text { anywhere along their travels }\end{array}$ & 5 \\
\hline Multimedia usage & $\begin{array}{l}\text { To understand television programs, movies, song } \\
\text { lyrics and social media, technology and the internet }\end{array}$ & 6 \\
\hline Education purpose & $\begin{array}{l}\text { To be able to pursue post-secondary studies/graduate } \\
\text { programs abroad }\end{array}$ & 7 \\
\hline
\end{tabular}

Surprisingly, motivational factor number one was labor market either in KSA or abroad. Saudi females reported that becoming bilingual is a way toward working in the KSA industry and corporations as well as their open window of opportunities overseas. In one of the narratives a writer said: "I would like to become independent and learning English will give me that sense of freedom and the opportunity to work in a foreign corporation in the future". Another writer said "My family spoke English especially when they were discussing business investment proposals, building plans, and interior decoration businesses. I picked up about the importance of the English language for business and for that I decided that to be highly accepted in the family business, English should be my second language".

Personal communication with foreigners and expatriates was ranked as number two among the 67 young Saudi girls. A strong need to meet people from other lands, to know more about their needs and wants, to exchange information about culture and social codes were a major part of the motivation to become bilinguals. Number 3 and 4 , English-speaking sibling and family encouragement are ranked among the five tops motivational factors that have served as the driving forces to become bilingual, English-Arabic. Nadia said in her essay that "My parents were the 
first two people in my life who encouraged and supported me to learn English. There are many reasons why they wanted me to speak English: they do not speak the language and English is the most important language in the world". Sameera wrote about her parents as well. She said "My parents have always pushed me, they work hard just to let me be better. So I joined an academy to learn English. I learned in the academy that I have to re-read everything to be able to understand". Salma referred to her parents sending her overseas, to England, when she was seventeen years old to attend English as a second language institute. Traveling is another factor that motivates the young female students to become bilingual. Many of the convenience sample, 32 out of 67 mentioned traveling and how English is used everywhere they went. For their future travel plans, the students mentioned the importance of knowing and using English as a second language.

Table 2 shows a description of the five Ws (who, what, when, where, and why), technique encouraged to make students write more than three paragraphs. After examining the narrative stories, a list of indicators were extracted. Commonalities were compiled. For example, the use of Who refer to parents, siblings, and friends who were the motivators to become bilinguals. For example, Shanoon said "when I was a child my parents read stories for me and my sisters at sleeping time". "My mother taught me how to count numbers in English", said Runna. The narratives referred to friends as the competitive factor to learn the language.

Table 2. The 5 Ws (who, what, when, where, and why)

\begin{tabular}{ll}
\hline 5 Ws & Describe/Explain/Evaluate \\
\hline Who & Parents, siblings, friends \\
What & English with purpose in mind \\
When & K-12 \\
Where & KSA and overseas \\
Why & Motives vary \\
\hline
\end{tabular}

The What showed learning English with a purpose in mind (traveling, studying abroad, doing business). The question When the foreign language was learned, the responses were somehow between Kindergarten to high school. Most students attended international schools. In the essays the Where the learning happened was identified as either the Kingdom of Saudi Arabia or foreign countries such as England and the United States. Several reasons were provided to learn English. Those themes were gathered in Table 1.

It became a relevant piece of information from the narrative analyzed that private schools are a common theme amongst the participants' narratives. Since most public schools did not offer English language instruction and as a result, many parents enrolled their children in private schools, so that they would be able to have the chance to learn English from a native English speaker such as an American, British or Canadian teacher at an early age.

\section{Discussion}

Most researchers suggest that motivation is crucial in the acquisition of a second language or becoming bilingual. In fact, Dornyei (1994) and Oxford (1994) already claimed that motivation was one of the most significant factors of success for learning a new language. Shahid \& Grami, (2013) using a sample of fifty-six Saudi students, found that their purpose for learning English was less academic and more sociable. Those findings correspond with what the young Saudi students revealed in the narrative stories they wrote about motivation to become bilingual. Their motivation to learn a second language varied as well as their favorable attitudes toward learning a language.

The work of Garner (2010) was reinforced in the study as it emphasized that motivation could be integrative or instrumental. The sample demonstrated both types of motivation. They showed integrative motivation because they have the desire to obtain something practical or concrete from the study of a second language. But they also evidenced instrumental motivation because they use the language to pass a school examination, to communicate with foreigners/expatriates, to connect in social media, and to travel to foreign lands.

Regardless of the level of motivation gathered in the essays, and the literature supporting motivation as an indicator for becoming bilingual, the Gulf States remain reluctant to accept motivation as the intrinsic factor to mobilize the individual learner to learn a second language. The previous paragraph does not support what is believed and 
researched by MacIntyre, MacMaster, and Baker (2001) that says that "motivation represents one of the most appealing, yet complex variables used to explain individual differences in language learning" ( p. 462).

Many limitations can be identified in conducting this qualitative research. First, the gender issue is one restraint. Not being able to set comparisons between male and female in terms of their motivation to become bilinguals can be considered a limitation. The use of a convenience only female sample should be corrected in future research studies if motivation is studied as an intrinsic factor that drives individuals to do things they want to do. Another major limitation was using a course assessment as the basis for data collection. For further research, the researchers must conduct the research away from the classroom grading system. Focus groups could be used to obtain the data from subjects that are free participants of the research process.

The significance of the study resides on providing more content to a body of knowledge in which becoming bilingual is researched. The literature uses indistinctively words such as "learning a foreign language", "becoming bilingual", "learning a second language", and "learning English as a second language". The only term that unifies the research studies is the construct motivation. For that reason, motivation represents a highly regarded factor that would bring serious benefits to all higher education institutions not only in Saudi Arabia but the rest of the Middle East countries when they plan for opening programs for learning a second language or as a foreign language. Motivation must be defined from the beginning and concrete elements must be incorporated to the curriculum in order to reach intrinsic or extrinsic, integrative or instrumental motivational factors.

\section{References}

Central Intelligency Agency (CIA). (2015). The World Factbook. Retrieved from https://www .cia .gov/library/publications/the-world-factbook/

Dörnyei, Z. (1994). Motivation and Motivating in the Foreign Language Classroom. The Modern Language Journal, 78(3), 273-284.

Foley, S. (2015). Legitimizing transformation without calling it change: Tajdid, Islah, and Saudi Arabia's place in the contemporary world. Contemporary Review of the Middle East, 2(1\&2), 55-70. https://doi.org/10.1177/2347798915577717

Gall, M. D., Gall, J. P., \& Borg, W. R. (2010). Applying educational research (6 $6^{\text {th }}$ ed.). Pearson: Boston, MA.

Gardner, R. (2010). Motivation and Second Language Acquisition: The Socio-Educational Model. UK: Peter Lang.

Gardner, R. C. (2006). The Socio-educational Model of Second Language Acquisition: AResearch Paradigm. Eurosla Yearbook, (6), 237-260.

Johnson, A. (2009). The Rise of English: The Language of Globalization in China and the European Union. Macalaster International, (12), 22.

Labov, W; \& Waletzky, J. (1967). Narrative analysis: Oral versions of personal experiences. In Helm J. (Ed.), Essays on the verbal and visual artes (pp. 12-44). Seattle; Universit of Washington Press.

MacIntyre, P. D., MacMaster, K., \& Baker, S. C. (2001). The convergence of multiple models of motivation for second language learning: Gardner, Pintrich, Kuhl, and McCroskey. In Z Dornyei \& R. Schmidt (Eds.), Motivation and second language acquisition (Technical Report \#23, pp. 461-492). Honolulu: University of Hawai'i, Second Language Teaching and Curriculum Center.

Moskovsky, Ch., \& Alrabia, F. (2009). Intrinsic Motivation in Saudi Learners of English as a Foreign Language. The Open Applied Linguistics Journal, (2), 1-10.

Oxford, R. L. (1994). Where are we with language learning motivation?. Modern Language Journal, 78(4), 512-514.

Renard, A. L. (2013). Young urban Saudi women's transgressions of official rules and the production of a new social group. Journal of Middle East Women's Studies, 9(3), 108-135. Retrieved from https://muse.jhu.edu/login?auth=0\&type=summary\&url=/journals/journal_of_middle_east_womens_studies/v0 09/9.3.le-renard.html

Schmitt, N. (2002). An Introduction to Applied Linguistics. Arnold: London.

Shahid, M. Y., \& Grami, M. G. (2013). The Role of Motivation in Language Achievement: A Self-Reporting Study of University Students. Official Conference Proceedings of the European Conference on the Social Sciences 2013. Retrieved from http://www.iafor.org

The Economist. (December 2001). A World Empire by Other Means-The Triumph of English. 